\title{
JURNAL KEPERAWATAN
}

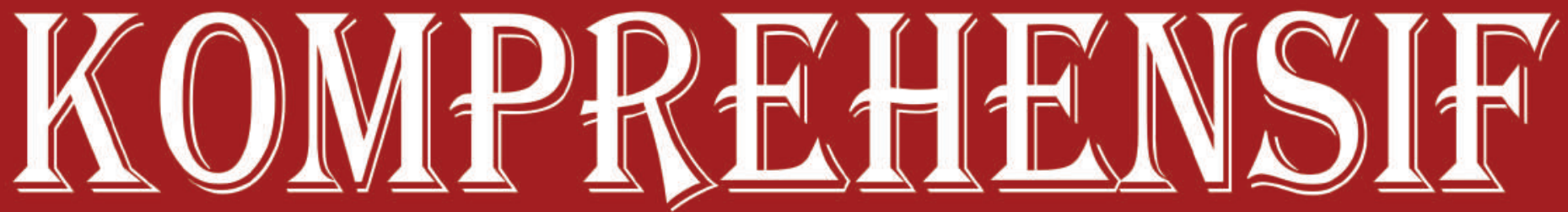

\section{COMPREHENSIVE NURSING JOURNAL}

\section{Sekolah Tinggi IImu Keperawatan}

Volume 5 No. 2, Juli 2019 PPNI Jawa Barat

Pengaruh Penerapan Panduan Perilaku Caring terhadap Peningkatan Perilaku Caring Mahasiswa di Fakultas Keperawatan Universitas Padjadjaran

(Rizka Aisyah, Aat Sriati, Valentina B.M.L)

Kompetensi Perawat Hemodialisis

(Irma Hermalia, Krisna Yetti, M. Adam)

Gambaran Penggunaan dan Tingkat Kecanduan Internet pada Siswa-Siswi SMA X di Jatinangor (Dian Dewi Novianti, Aat Sriati, Ahmad Yamin)

Upaya Pasien dan Keluarga Penderita TB Paru dalam Mempertahankan Status Gizi :

Studi Kualitatif

(Nur Lailatul Masruroh, Anggraini Dwi Kurnia, Nur Melizza)

Tingkat Aktivitas Fisik pada Lansia di Provinsi Jawa Barat, Indonesia

(Heni Purnama, Tia Suhada)

Gambaran Kontrol Diri Penggunaan Smartphone pada Siswa Sekolah Menengah Atas dan

Sederajat di Kecamatan Jatinangor

(Wulan Selvia Andriani, Aat Sriati, Ahmad Yamin)

Gambaran Harga Diri Pasien Diabetes Mellitus yang Mengalami Ulkus Diabetik di Rumah

Perawatan Luka Bandung

(Hermin Setiorini, Tuti Pahria, Titin Sutini)

\begin{tabular}{|c|c|c|c|c|c|}
\hline $\begin{array}{c}\text { JURNAL KEPERAWATAN } \\
\text { KOMPREHENSIF }\end{array}$ & VOL. 5 & NO. 2 & Hal. 64-126 & $\begin{array}{c}\text { ISSN } \\
\text { Bandung } \\
\text { Juli } \\
2019\end{array}$ & $\begin{array}{c}2354-8428 \\
\text { e-ISSN } \\
2598-8727\end{array}$ \\
\hline
\end{tabular}




\title{
GAMBARAN KONTROL DIRI PENGGUNAAN SMARTPHONE PADA SISWA SEKOLAH MENENGAH ATAS DAN SEDERAJAT DI KECAMATAN JATINANGOR
}

\author{
Wulan Selvia Andriani', Aat Sriati ${ }^{2}$, Ahmad Yamin ${ }^{3}$ \\ ${ }^{1,2}$ Fakultas Keperawatan Universitas Padjadjaran \\ ${ }^{3}$ Mahasiswa Fakultas Universitas Padjadjaran \\ wulan14001@mail.unpad.ac.id
}

\begin{abstract}
Abstrak
Penggunaan smartphone yang berlebihan menyebabkan kecanduan smartphone dan nomophobia hingga berdampak gangguan mental komorbiditas. Hal ini dapat diantisipasi dengan adanya kontrol diri, seharusnya mereka mampu untuk mengatur dan menjalankan tugas sebagai pelajar sehingga tidak mengalami kecanduan smartphone. Tujuan dari penelitian ini adalah untuk mengidentifikasi kontrol diri penggunaan smartphone pada siswa SMA dan Sederajat di Kecamatan Jatinangor. Metode penelitian menggunakan deskriptif kuantitatif dengan populasi berjumlah 2.376 siswa dan sampel sebanyak 342 responden yang menggunakan teknik proportional sample random sampling. Pengambilan data menggunakan Skala Kontrol Diri yang dimodifikasi dari Rika (2012) dengan nilai validitas antara 0,431-0,783 dan koefisien alpha croncbah 0,919. Terdiri dari 27 item pernyataan menggunakan skala likert $1-5$. Data dianalisis menggunakan distribusi frekuensi dan presentase dari setiap sub-variabel. Hasil penelitian menunjukan bahwa kontrol diri penggunaan smartphone pada siswa menyebar dalam tiga kategori yakni kontrol diri tinggi $(15,8 \%)$, kontrol diri sedang $(80,7 \%)$, dan kontrol diri rendah terhadap penggunaan smartphone (3,5\%). Kesimpulan penelitian ini adalah persentase terbesar partisapan memiliki kontrol diri sedang terhadap penggunaan smartphone, artinya partisipan tidak selalu melakukan pengendalian terhadap semua impuls memainkan smartphone yang partisipan miliki. Rekomendasi hasil penelitian ini agar perawat komunitas dan pihak sekolah membentuk program untuk mencegah penggunaan smartphone agar tidak berlebihan melalui berbagai sumber informasi, terutama sumber informasi yang signifikan bagi remaja.
\end{abstract}

Kata Kunci : Kontrol Diri, Smartphone, Remaja

\begin{abstract}
Excessive use of smartphone causes smartphone addiction and nomophobia, even leads to comorbid mental disorders. It can be anticipated by self-control, they should be able to control and carry out their duties as students so they do not experience smartphone addiction. The purpose of this study was to identify self-control of smartphone usage among high school students in Jatinangor District. The research method used quantitative descriptive with a population of 2.376 students and a sample of 342 respondents using proportional sample random sampling technique. Data collection using a modified Self Control Scale by Rika (2012) with validity values between 0.424-0.778 and alpha Cronbach coefficient 0.919. The instrument consists of 27 statement items using a 1 - 5 Likert scale. Data were analyzed using frequency distribution and percentage of each sub-variable. The results showed that self-control of smartphone usage among students was divided into three categories: high self-control (15.8\%), moderate self-control $(80.7 \%)$ and low self-control of smartphone usage (3.5\%). In conclusion, the largest percentage of participants had moderate self-control of smartphone usage which meant that participants do not always control the impulses to play the smartphone that participants have. This study recommends that community nurses and the school of programs to prevent the excessive usage of smartphones through various sources of information, especially significant sources for adolescents.
\end{abstract}

Key Words : Self Control, Smartphone Usage, Adolescents 


\section{PENDAHULUAN}

Perkembangan zaman terus menerus mengikuti arus globalisasi, yang berakibat semakin marak penggunaan smartphone. Dahulu penggunaan smartphone hanya untuk panggilan, dan mengirim pesan, kini memiliki banyak fungsi, dan memiliki fungsi menyerupai komputer (Backer, 2010). Kondisi maraknya penggunaan smartphone, menyebabkan Indonesia menempati peringkat ke 3 jumlah pengguna smartphone terbanyak di Asia Pasifik sekitar 65.2 juta pengguna (eMarketer, 2016). Di Indonesia dalam mengakses internet, paling banyak menggunakan smartphone yaitu pulau Jawa dan Bali sekitar 92\% (PUSKAKOM, 2015). Berdasarkan hasil Penelitian Kementerian Komunikasi dan Informatika yang didukung oleh UNICEF Indonesia sekitar 80\% anakanak dan remaja yang berusia 10 sampai 19 tahun menggunakan internet dan sebagian besar mengakses internet menggunakan smartphone (52\%) (UNICEF Indonesia, 2014). Remaja merupakan salah satu kelompok yang mudah terpengaruh baik pengaruh positif maupun negatif (Hanifah, 2013).

Dampak dari penggunaan smartphone yang dilakukan secara berlebihan akan menyebabkan gangguan tidur, stres, kecemasan, memburuknya kesehatan, penurunan kinerja akademis dan fisik (Thomee, Harenstam, \& Hagberg, 2011). Dikatakan berlebihan dalam penggunaan smartphone akibat dari penggunaannya yang dilakukan secara terus-menerus dan tidak menentu sehingga dapat mengarah pada kecanduan. Selain itu, dampak negatif dari penggunaan smartphone yaitu menyebabkan kecanduan, malas belajar, boros, dan berkurangnya interaksi sosial (Putri, 2015).
Smartphone memiliki pengaruh terhadap pola pemikiran remaja, menyebabkan mereka malas dalam melakukan sosialisasi, lunturnya jiwa sosial, dan perubahan pola interaksi (Fajrin, 2013). Sehingga penggunaan smartphone yang berlebihan ini mengakibatkan dampak negatif pada individu tersebut.

Agusta (2016) menyatakan bahwa salah satu faktor yang paling dominan mempengaruhi kecanduan penggunaan smartphone adalah faktor internal dengan aspek yang paling tinggi mempengaruhi kecanduan smartphone yaitu kontrol diri yang rendah. Sehingga kontrol diri memainkan peranan dalam penggunaan smartphone. Remaja yang memiliki smartphone diharapkan mempunyai keterampilan dalam mengatur perilakunya yang sesuai dengan nilai dan norma yang dianut di masyarakat, dan terhindar dari perilaku yang menyimpang. Keterampilan ini disebut dengan istilah kontrol diri. Averill (1973 ; dalam Ghufron \& Resnawati, 2014) mengemukakan bahwa kontrol diri memiliki tiga aspek yaitu kontrol kognitif (information gain dan appraisal), kontrol keputusan dan kontrol perilaku (regulated administration dan stimulus modification). Aspek- aspek tersebut bekerja saling berkesinambungan, dimana aspek sebelumnya akan mempengaruhi aspek selanjutnya.

Berdasarkan hasil penelitian didapatkan $51,1 \%$ remaja menggunakan smartphone 3-5 jam dalam sehari, dan 22,2 \% remaja lebih dari 6 jam durasi waktu menggunakan smartphone (Noviana, 2016). Durasi penggunaan smartphone ini berkaitan dengan sebarapa lama seseorang dalam menggunakan smartphone, dan durasi penggunaan smartphone merupakan salah satu aspek dalam mengukur intensitas 
penggunaan smartphone (Charunnisa, 2010). Durasi ini berpengaruh terhadap pengendalian diri yang dimiliki individu. Selain itu, jenis kelamin memiliki peranan dalam mempengaruhi tingkat kecanduan smartphone (Bouzza, Al-Barashdi, dan Zubaidi, 2015). Gottfredson \& Hirschi dalam Gibson (2010) mengemukakan bahwa terdapat perbedaan antara kontrol diri laki-laki dengan perempuan.

Jumlah pasar yang besar secara Nasional menunjukkan bahwa penggunaan smartphone mendapatkan penerimaan yang baik dari masyarakat di berbagai daerah. Salah satu daerah yang juga ikut terkena 'demam' penggunaan smartphone adalah Jatinangor, sebuah Kecamatan di Kabupaten Sumedang yang tidak lain merupakan kawasan pendidikan tinggi yang mayoritas penduduk aslinya merupakan remaja. Salah satu tingkat pendidikan yang memperbolehkan para pelajar membawa smartphone ke sekolah adalah tingkat Sekolah Menengah Atas/ SMA dan Sederajat.

Berdasarkan observasi yang dilakukan peneliti pada bulan Januari 2018 pada salah satu Sekolah Menengah Atas dan Sederajat di Kecamatan Jatinangor, hampir setiap kelas diam-diam menggunakan smartphone ketika guru sedang mengajar maupun rekannya yang sedang berbicara dihadapan mereka dan menurut guru bidang Bimbingan dan Konseling (BK) terdapat kasus bahwa beberapa siswa tiap kelas tidak menyelesaikan tugas tepat waktu. Selain melakukan observasi, untuk menunjang data, peneliti juga melakukan wawancara pada bulan Juli 2018 kepada 5 siswa Sekolah Menengah Atas dan Sederajat di Kecamatan Jatinangor yang memiliki smartphone.

Berdasarkan jawaban yang diberikan responden, 4 dari 5 berusaha meluangkan waktunya untuk menggunakan smartphone dengan durasi yang cukup lama yakni lebih dari 5 jam sehari. Mereka mengaku bahwa kegiatan belajar di sekolah seringkali terganggu (seperti penundaan tugas sekolah, dan menjadi tidak fokus belajar) karena kesulitan membatasi penggunaan smartphone, selain itu mereka merasa gelisah bila tidak memainkan smartphone. Mereka cenderung lebih memainkan smartphone, sehingga melalaikan tugas sebagai pelajar. Namun didapatkan pula siswa yang membatasi penggunaan smartphone, sehingga tidak terganggu kegiatan belajar di sekolah. Siswa memerlukan pengarahan dalam perilakunya sehingga dapat memenuhi tugasnya sebagai pelajar. Pengarahan dan pengaturan ini terkait dengan kontrol diri. Hal tersebut akan terwujud dengan adanya dukungan dari berbagai pihak baik dari keluarga, pihak sekolah serta perawat kesehatan sekolah yang memiliki tugas dalam menciptakan healthy school. Disini, perawat melakukan kegiatan preventif maupun promotif untuk warga sekolah (guru, pelajar, staf tata usaha, dll) (Swarjana, 2016).

Uraian diatas, peneliti melihat adanya fenomena penggunaan smartphone yang tinggi pada remaja dan faktor tertinggi yang mempengaruhi penggunaan smartphone yaitu kontrol diri yang rendah. Sehingga peneliti ingin meneliti gambaran kontrol diri penggunaan smartphone pada siswa Sekolah Menengah Atas dan Sederajat di Kecamatan Jatinangor.

\section{METODE PENELITIAN}

Penelitian ini menggunakan rancangan penelitian deskriptif dengan pendekatan kuantitatif yang bertujuan untuk mengidentifikasi kontrol diri penggunaan smartphone pada siswa Sekolah Menengah Atas dan Sederajat di Kecamatan Jatinangor. 
Variabel yang digunakan terdiri dari satu variabel independen yaitu kontrol diri.

Populasi dalam penelitian ini adalah seluruh siswa Sekolah Menengah Atas dan Sederajat di Kecamatan Jatinangor yang telah disesuaikan dengan karakteristik untuk sampel penelitian, yaitu sebanyak 2.376 siswa. Teknik pengambilan sampel yang digunakan dalam penelitian adalah Proportional Random Sampling dalam menentukan sampel untuk masing-masing sekolah, selanjutnya teknik pengambilan sampel tiap sekolah menggunakan metode Simple Random Sampling dengan cara acak angka menggunakan komputer excel random yang sebelumnya peneliti urutkan terlebih dahulu data siswa tiap sekolah.

Instrumen pengumpulan data yang digunakan dalam penelitian ini adalah skala kontrol diri yang dimodifikasi dari Rika (2012) dengan menggunakan aspek-aspek kontrol diri yāng dikemukakan Averill, terdiri dari 3 aspek kontrol diri dan 5 indikator kontrol diri yang telah dijabarkan dari ketiga aspek kontrol diri. Alat ukur yang digunakan pada skala ini yaitu menggunakan skala likert dengan dua sifat pernyataan yaitu pernyataan positif (favorable) dari selalu sampai tidak pernah (5-1) dan negatif (unfavorable) dari selalu sampai tidak pernah (1-5). Skala kontrol diri ini dilakukan uji validitas dan reliabilitas, didapatkan hasil dengan nilai validitas antara 0,431-0,783 yang dikatakan valid dan koefisien alpha croncbah 0,919 dinyatakan reliabel. Kuisioner ini terdiri dari data demografi dan skala kontrol diri penggunaan smartphone. Peneliti mengolah data dengan program SPSS (Statistical Product and Service Solution). Data yang diperoleh dikategorisasikan berdasarkan skoring, kemudian dianalisis dengan menggunakan distribusi frekuensi dan presentase dari setiap sub-variabel. Dalam menentukan kategori skor total kontrol diri terhadap penggunaan smartphone yaitu dengan rumus (Rika, 2012):

1. Menentukan hasil skor tertinggi yang mungkin dicapai, yaitu lima dikali jumlah item/pernyataan.

2. Menentukan hasil skor terendah yang mungkin dicapai, yaitu satu dikali jumlah item.

3. Menentukan selisih skor tertinggi dan skor terendah, yang kemudian dibagi dengan jumlah kategori yang diinginkan, yaitu tiga kategori.

Distribusi proporsi dilakukan dengan melakukan perhitungan persentase dari frekuensi terhadap jumlah seluruh responden dengan rumus berikut (Sugiyono, 2014) :

$$
P={ }_{n}^{f} \times 100 \%
$$

Keterangan :

$$
\begin{array}{ll}
P & : \text { Persentase } \\
F & : \text { frekuensi dari setiap jawaban angket } \\
N & : \text { Jumlah total responden }
\end{array}
$$

\section{HASIL PENELITIAN}

Penelitian ini mendapatkan hasil bahwa presentase terbesar responden berada pada kelompok dengan kontrol diri sedang $80,7 \%$, didapatkan pula responden dengan kontrol diri tinggi $15,8 \%$ dan sisanya 3,5\% memiliki kontrol diri rendah terhadap penggunaan smartphone pada siswa Sekolah Menengah Atas dan Sederajat di Kecamatan Jatinangor. Hal tersebut dijelaskan pada tabel berikut : 


\begin{tabular}{cccc}
\hline No. & Karakteristik & Frekuensi (f) & Persentase \\
\hline $\mathbf{1}$ & Kontrol Diri Tinggi & 54 & $15,8 \%$ \\
$\mathbf{2}$ & Kontrol Diri Sedang & 276 & $80,7 \%$ \\
$\mathbf{3}$ & Kontrol Diri Rendah & 12 & $3,5 \%$ \\
\hline & Total & $\mathbf{3 4 2}$ & $\mathbf{1 0 0 \%}$ \\
\hline
\end{tabular}

Didapatkan pula hasil penelitian yang menjabarkan aspek-aspek yang menbentuk kontrol diri, dimulai dari kontrol kognitif (information gain \& appraisal), selanjutnya memasuki kontrol keputusan, dan terakhir memasuki kontrol perilaku (regulated administration \& stimulus modification). Berdasarkan hasil penelitian didapatkan bahwa sebagian besar baik kontrol kognitif (information gain \& appraisal), kontrol keputusan, dan kontrol perilaku (regulated administration \& stimulus modification) berada pada kategori sedang. Hal ini dikarenakan dalam pembentukan kontrol diri, aspek pertama akan mempengaruhi aspek selanjutnya. Dapat dilihat pada tabel berikut:

\begin{tabular}{|c|c|c|c|c|c|}
\hline No & Aspek & Kategori & Frekuensi & Presentasi & Total \\
\hline \multirow[t]{3}{*}{1} & Kontrol Kognit if & Tinggi & 122 & $35,7 \%$ & $100 \%$ \\
\hline & & Sedang & 210 & $61,4 \%$ & \\
\hline & & Rendah & 10 & $2,9 \%$ & \\
\hline \multirow[t]{3}{*}{2} & Kontrol & Tinggi & 52 & $15,2 \%$ & $100 \%$ \\
\hline & Keputusan & Sedang & 280 & $81,9 \%$ & \\
\hline & & Rendah & 10 & $2,9 \%$ & \\
\hline \multirow[t]{3}{*}{3} & Kontrol Perilaku & Tinggi & 45 & $13,2 \%$ & $100 \%$ \\
\hline & & Sedang & 275 & $80,4 \%$ & \\
\hline & & Rendah & 22 & $6,4 \%$ & \\
\hline No & Aspek & Kategori & Frekuensi & Presentasi & Total \\
\hline \multirow[t]{3}{*}{1} & Information gain & Tinggi & 147 & $43 \%$ & $100 \%$ \\
\hline & & Sedang & 188 & $55 \%$ & \\
\hline & & Rendah & 7 & $2 \%$ & \\
\hline \multirow[t]{3}{*}{2} & Appraisal & Tinggi & 134 & $39,2 \%$ & $100 \%$ \\
\hline & & Sedang & 202 & $59 \%$ & \\
\hline & & Rendah & 6 & $1,8 \%$ & \\
\hline No & Aspek & Kategori & Frekuensi & Presentasi & Total \\
\hline \multirow[t]{3}{*}{1} & Regulated & Tinggi & 52 & $15,2 \%$ & $100 \%$ \\
\hline & administration & Sedang & 280 & $81,9 \%$ & \\
\hline & & Rendah & 10 & $2,9 \%$ & \\
\hline \multirow[t]{3}{*}{2} & Stimulus & Tinggi & 69 & $20,2 \%$ & $100 \%$ \\
\hline & modification & Sedang & 251 & $73,4 \%$ & \\
\hline & & Rendah & 22 & $6,4 \%$ & \\
\hline
\end{tabular}


Selain itu, penelitian ini juga mendapatkan hasil bahwa jenis kelamin laki- laki memiliki kontrol diri lebih rendah terhadap penggunaan smartphone daripada perempuan. Ditemukan pula hasil bahwa semakin lama durasi penggunaan smartphone, maka semakin rendah kontrol diri yang dimiliki individu tersebut. Hal tersebut peneliti jelaskan dalam tabel sebagai berikut :

\begin{tabular}{ccccccc}
\hline No & Jenis Kelamin & Jumlah & Kategori & Frekeunsi & Presentasi & Total \\
\hline 1 & Laki-laki & 152 & Tinggi & 23 & $15,1 \%$ & $100 \%$ \\
& & & Sedang & 122 & $80,3 \%$ & \\
\multirow{2}{*}{2} & & & Rendah & 7 & $4,6 \%$ & \\
& \multirow{2}{*}{ Perempuan } & \multirow{2}{*}{190} & Tinggi & 31 & $16,3 \%$ & $100 \%$ \\
& & & Sedang & 154 & $81,1 \%$ & \\
\hline
\end{tabular}

\begin{tabular}{|c|c|c|c|c|c|}
\hline \multirow{2}{*}{$\begin{array}{c}\text { Kontrol } \\
\text { Diri }\end{array}$} & \multicolumn{3}{|c|}{ Durasi Memainkan Smartphone /Hari } & \multirow{2}{*}{$\begin{array}{l}\text { Jumlah } \\
\text { Subjek } \\
\end{array}$} & \multirow{2}{*}{ Persentase } \\
\hline & $\leq 2$ jam & 3-5 Jam & $\geq 6$ jam & & \\
\hline Tinggi & 20 & 24 & 10 & 54 & $15,8 \%$ \\
\hline Sedang & 68 & 121 & 87 & 276 & $80,7 \%$ \\
\hline Rendah & 2 & 4 & 6 & 12 & $3,5 \%$ \\
\hline \multirow{2}{*}{ Total } & 90 & 149 & 103 & \multirow{2}{*}{342} & \multirow{2}{*}{$100 \%$} \\
\hline & & 342 & & & \\
\hline
\end{tabular}

\section{PEMBAHASAN}

Pada data hasil penelitian, diketahui bahwa persentase terbesar partisipan $(80,7 \%)$ siswa Sekolah Menengah Atas dan Sederajat di Kecamatan Jatinangor memilki kontrol diri yang sedang terhadap penggunaan smartphone. Siswa yang memiliki kontrol diri sedang terhadap penggunaan smartphone, artinya siswa tersebut berada pada rentang dapat menuju kontrol diri tinggi ataupun menuju kontrol diri rendah. Hal tersebut mengindikasikan bahwa partisipan sudah berusaha mengendalikan implusnya dalam memainkan smartphone agar tetap seimbang dengan kegiatan lainnya yang harus dilakukan, namun pengendalian tersebut tidak selalu partisipan lakukan di setiap kali ia mendapat kesempatakan memainkan smartphone. Dengan kata lain, terdapat beberapa kesempatan dimana partisipan tidak menjalankan fungsi pengendaliannya terhadap implus.

Terdapat sebanyak $15,8 \%$ siswa Sekolah Menengah Atas dan Sederajat di Kecamatan Jatinangor yang memiliki kontrol diri tinggi terhadap penggunaan smartphone. Widiana, Retnowati, dan Hidayat (2004) mengungkapkan bahwa individu yang memiliki kontrol diri yang tinggi akan menggunakan internet (merupakan salah satu fitur pada smartphone) secara sehat dan sesuai dengan kebutuhannya. Dalam hal ini, siswa memiliki inisiatif untuk mencari dan mengkaitkan informasi yang tepat mengenai penggunaan smartphone, mampu menggunakan informasi tersebut untuk melakukan penilaian negatif maupun positif terhadap penggunaan smartphone dan memilih cara-cara pencegahan penggunaan smartphone agar tidak berlebihan yang sesuai 
dengan kondisi yang dialami, mampu untuk mengendalikan stimulus kenikmatan memainkan smartphone dari dalam diri dan mampu untuk mencegah penggunaan smartphone agar tidak berlebihan.

Dalam membedakan siswa yang memiliki kontrol diri tinggi dengan siswa kontrol diri sedang terhadap penggunaan smartphone ialah pada inisiatif untuk mencari informasi dari berbagai sumber informasi dan kepemilikan informasi yang tepat (Hanafitri, 2016). Siswa dengan kategori terakhir dan dengan jumlah yang paling sedikit $(3,5 \%)$ ialah siswa Sekolah Menengah Atas dan Sederajat memiliki kontrol diri yang rendah terhadap penggunaan smartphone. Artinya, sebanyak 3,5\% siswa memiliki informasi yang kurang tepat dan hanya mampu mengkaitkan sebagian kecil informasi mengenai penggunaan smartphone, tidak mampu memberi penilaian yang tepat mengenai penggunaan smartphone, memilih untuk memainkan smartphone yang berlebihan, dan tidak mampu mencegah penggunaan smartphone yang berlebihan.

Ketika siswa dihadapkan pada situasisituasi yang tidak sesuai dengan harapannya atau bertentangan dengan tujuan jangka panjangnya, maka kontrol diri bekerja berdasarkan aspek-aspek yang membentuknya. Berdasarkan hasil penelitian, diketahui bahwa sebagian besar siswa memiliki kontrol kognitif yang sedang. Pada aspek ini terdapat 2 sub aspek yang membantu siswa dalam membentuk kontrol kognitif yaitu information gain dan appraisal didapatkan hasil bahwa mayoritas siswa berada pada kategori sedang. Sub aspek yang pertama bekerja membentuk kontrol diri adalah information gain (Hanafitri, 2016). Berdasarkan data hasil bahwa mayoritas siswa memiliki information gain yang sedang terhadap penggunaan smartphone. Artinya, 113 siswa memiliki informasi dan cenderung mampu untuk mengkaitkan informasi yang dimiliki mengenai penggunaan smartphone, namun informasi tersebut tidak menyeluruh dan kurang tepat. Kurang tepat dan kurang menyeluruhnya informasi yang dimiliki pada akhirnya sering kali membuat siswa merasa ragu atau kurang yakin di dalam memberikan penilaian terhadap penggunaan smartphone dan cara-cara yang dapat dilakukan untuk mencegah penggunaan smartphone agar tidak berlebihan.

Berdasarkan hasil penelitian, mayoritas siswa memiliki kontrol keputusan yang sedang. Artinya siswa merasakan ragu di dalam mengambil keputusan untuk mencegah maupun memilih cara-cara pencegahan penggunaan smartphone agar tidak berlebihan karena lebih mempertimbangkan pendapat dari lingkungan. Setelah melalui aspek kontrol keputusan, maka siswa memasuki aspek regulated administration dan stimulus modification. Kedua aspek ini merupakan hasil akhir dari kontrol diri yang dapat dilihat melalui perilaku yang muncul dari para siswa. Berdasarkan data hasil didapatkan bahwa sebagian besar siswa memiliki kontrol perilaku yang sedang.

Mayoritas siswa memiliki regulated administration yang sedang. Dengan ini artinya, bahwa siswa hanya memiliki kemampuan untuk mengendalikan diri di dalam mencegah penggunaan smartphone agar tidak berlebihan. Didapatkan pula sebagian besar siswa memiliki stimulus modification yang sedang terhadap penggunaan smartphone. Artinya, bahwa siswa memiliki keraguan didalam mencegah penggunaan smartphone agar tidak berlebihan.

Menurut Horrigan (2000) durasi adalah jumlah waktu dan lama mengakses smartphone dalam sehari/seminggu maupun 
sebulan. Pada penelitian ini didapatkan data bahwa mayoritas siswa yang menjadi responden, dengan kontrol diri yang tinggi, dan sedang memainkan smartphone dengan durasi lebih dari 3-5 jam/hari. Namun pada siswa yang memiliki kontrol diri rendah memainkan smartphone dengan durasi $\geq 6$ jam/hari. Dengan ini durasi memainkan smartphone memiliki kaitannya dengan kontrol diri, semakin lama durasi memainkan smartphone, maka semakin rendah kontrol diri yang dimiliki terhadap penggunaan smartphone. Sejalan dengan penelitian Pramana (2018) bahwa seseorang yang mempunyai waktu penggunaan internet (salah satu fitur dalam memainkan smartphone) yang tinggi maka kontrol diri yang dimilikinya rendah. Didukung oleh hasil penelitian Young (1998) yang menyatakan bahwa durasi adalah salah satu cara yang menunjukan seberapa terikatnya seseorang dengan smartphone. Menurut Putra (2015) salah satu aspek pengaruh penggunaan smartphone yang tinggi yaitu frekuensi dan durasi penggunaannya. Durasipenggunaan smartphone berpengaruh terhadap kecanduan smartphone (Gokcearslan, Filiz, Tulin, \& Yasemin, 2016). Kecanduan smartphone ini dipengaruhi oleh beberapa faktor, dan faktor yang paling dominan menyebabkan seseorang mengalami kencanduan smartphone adalah kontrol diri yang rendah (Agusta, 2016). Sehingga durasi penggunaan smartphone ini memberikan pengaruh negatif pada perilaku seseorang.

Menurut hasil dari data penunjang, siswa laki-laki memiliki kontrol diri yang lebih rendah daripada perempuan terhadap penggunaan smartphone. Sejalan dengan teori yang dikemukakan oleh Gottfredson \& Hirschi (1990) dalam Gibson (2010) bahwa didapatkan perbedaan tingkat kontrol diri antara laki-laki dengan perempuan. Laki-laki mempunyai kontrol diri lebih rendah daripada perempuan. Sehingga banyak ditemukan tindakan negatif dan menyimpang pada lakilaki. Saat kontrol dirinya rendah maka individu tersebut akan menunjukan perilaku impulsif dan perilaku negatif yang berhubungan erat dengan perilaku agresif (Gottfredson \& Hirschi, 1990; dalam Gibson, 2010), perilaku negatif dalam penelitian ini adalah ketidakmampuannya dalam mengontrol diri terhadap penggunaan smartphone. Perbedaan kontrol diri ini dapat dilihat dari sifat perempuan yang apabila sedang stress ia akan cenderung merasakannya terlebih dahulu dan memikirkannya sebelum bertindak, serta respon yang dimunculkannya lebih berhatihati. Sedangkan pada laki-laki saat mengalami stress, ia cenderung bertindak terlebih dahulu, lalu kemudian baru berfikir, sehingga respon yang dimunculkannya lebih agresif serta beresiko (Muhammad, 2011).

Adapun proses meningkatkan aspek information gain dapat dilakukan dengan cara memberikan informasi dan pendidikan yang tepat mengenai penggunaan smartphone, dampak negatif yang akan ditimbulkan dari penggunaan smartphone yang berlebihan, dan cara-cara yang tepat untuk mencegah atau mengurangi penggunaan smartphone agar tidak berlebihan. Dengan memiliki pengetahuan dan informasi yang tepat maka siswa akan dapat memasuki proses selanjutnya pada aspek appraisal atau memberikan penilaian dan penafsiran terhadap objek atau stimulus yang dimaksud, dimana siswa dapat berpikir kritis untuk mempertimbangkan dampak negatif jangka panjang yang akan muncul apabila menggunakan smartphone yang berlebihan. Dengan kemampuan 
memberikan penilaian yang baik, maka seseorang akan dapat memasuki tahap selanjutnya yakni memilih atau mengambil keputusan sendiri/ kontrol keputusan. Melalui kemampuannya di dalam memilih atau mengambil keputusan yang kuat untuk mencegah penggunaan smartphone agar tidak berlebihan, maka seseorang akan dapat dengan mantap mengambil keputusan untuk mencegah atau mengurangi penggunaan smartphone agar tidak berlebihan meskipun banyak faktor di luar diri yang akan mempengaruhinya.

Setelah mengambil keputusan dengan keyakinan yang kuat untuk mencegah penggunaan smartphone agar tidak berlebihan dengan berbagai modal informasi dan penilaian terhadap penggunaan smartphone, dampak negatif penggunaan smartphone, dan cara-cara yang dapat dilakukan, maka individu akan dapat memasuki tahapan atau aspek selanjutnya yakni regulated administration dan stimulus modification. Melalui bekal atau modal yang dimiliki sebelumnya pada aspek information gain, appraisal dan kontrol keputusan yang kuat akan membuat siswa dapat mengambil kendali atas diri dan lingkungannya, serta memodifikasi atau mengubah stimulus untuk mencegah penggunaan smartphone agar tidak berlebihan dan sesuai dengan pengetahuan yang dimilik serta kondisi yang ia alami.

Peningkatan kualitas perlu dilakukan karena manfaat dari kontrol diri untuk diri sendiri. Schneiders (1964) mengemukakan bahwa kontrol diri merupakan dasar dari pengembangan diri, suatu peningkatan secara terus menerus dalam kematangan kepribadian terhadap tujuan dan pencapaian pribadi; sehingga apabila kontrol diri partisipan meningkat dan optimum di seluruh aspeknya maka kontrol diri itu dapat menjadi bekal bagi mereka untuk dapat menjadi pribadi yang lebih matang lagi di masa depan karena dapat menyimbangkan kegiatan yang disenanginya dengan kewajibanya.

\section{SIMPULAN}

Hasil penelitian bahwa secara umum, partisipan penelitian menunjukan kemampuan kontrol diri yang tergolong sedang terhadap penggunaan smartphone $(80,7 \%)$, yang berarti pada umumnya partisipan berada pada rentang antara menuju kontrol diri tinggi ataupun dapat juga menuju kontrol diri rendah terhadap penggunaan smartphone. Dalam hal ini, kontrol diri partisipan tergolong sedang yang menunjukkan bahwa partisipan tidak selalu melakukan pengendalian terhadap semua impuls memainkan smartphone yang partisipan miliki.

Dalam membentuk kontrol diri didapatkan serangkaian aspek-sapek yang bekerja membentuk kontrol diri. Pada aspekaspek yang berkerja membentuk kontrol diri pada Siswa Sekolah Menengah Atas dan Sederajat di Kecamatan Jatinangor yaitu sebagian besar memiliki kontrol kognitif sedang $(61,4 \%)$, kontrol keputusan sedang $(81,9 \%)$, dan kontrol perilaku sedang $(80,4 \%)$. Aspek-aspek kontrol diri ini bekerja secara bertahap hingga membentuk kontrol diri terhadap penggunaan smartphone mulai dari aspek information gain hingga pada aspek stimulus modification, sehingga setiap aspek akan ditentukan oleh aspekaspek sebelumnya di dalam membentuk kontrol diri. Aspek-aspek tersebut bekerja melalui serangkaian proses yang berkesinambungan.

Data penunjang hasil penelitian pada Siswa Sekolah Menengah Atas dan Sederajat di Kecamatan Jatinangor mengenai jenis kelamin dengan kontrol diri terhadap 
penggunaan smartphone bahwa jenis kelamin laki-laki memiliki kontrol diri lebih rendah dibandingkan jenis kelamin perempuan. Didapatkan pula bahwa semakin lama durasi memainkan smartphone maka kontrol diri yang dimilikinya terhadap pengggunaan smartphone semakin rendah.

Dari hasil penelitian, peneliti memberikan rekomendasi pada perawat komunitas dan pihak sekolah untuk membuat sebuah program untuk mencegah penggunaan smartphone agar tidak berlebihan melalui berbagai sumber informasi, terutama sumber informasi yang signifikan bagi remaja, serta memberikan batasan durasi penggunaan smartphone pada siswa.

\section{REFERENSI}

Agusta, D. (2016). Faktor-Faktor Resiko Kecanduan Menggunakan Smartphone. E-Journal Bimbingan dan Konseling, 86-96.

Backer, Elisa. (2010). Using Smartphone and Facebook in A Major Assessment: The Student Experience". E-Journal. Australia: University of Ballarat.

Bouazza, A., Al-Barashdi, H.S., Al Zubaidi, A.Q. (2015). Develompment and Validation of a Smartphone Addiction Questionnaire (SPAQ). Jurnal Sultan Qaboos University. 2, 5658.

Charunnisa. (2010). Hubungan Intensitas Mengakses Facebook Dengan Motivasi Belajar Siswa MAN 13 Jakarta. Skripsi SI tidak diterbitkan.

Emarketer. (2016). Pengguna Smartphone Tertinggi di Asia-Pasifik 2016. Retrieved October 26, 2017 from

https://databoks.katadata.co.id/datapubli sh/2016/08/08/pengguna--smartphone tertinggi-di-asia-pasifik-2016
Fajrin Nesy Aryani. (2013). Pengaruh penggunaan handphone terhadap pola pemikiran remaja di era globalisasi. Diambil dari http://digilib.uinsuka.ac.id/12123/1/BAB I\%2C V\%2C DAFTAR PUSTAKA.pdf

Ghufron, M. Nur \& Rini Risnawita S. (2014). Teori-Teori Psikologi. Jogjakarta: Ar-Ruzz Media.

Gibson, C. L. (2010). Encyopedia Of Cri Inological Theory: Gottfredson, Michael R., And Travis Hirschi: Self Control Theory. Thousand Oaks: SAGE: Publications Inc.

Gokcearslan, Sahin., Filiz K. M., Tulin H., \& Yasemin D. C. (2016). Modelling Smartphone addiction: The role of smartphone usage, sel-regulation, general self-efficacy and cyberloafing in university students. Computers in Human Behaviour, 63, 639-649. DOI: 10.1016/j.chb.2016.05.091

Hanafitri, Aulia. (2016). Tesis Rancangan Program Intervensi Untuk Meningkatkan Kontrol Diri Terhadap Perilaku Seksual Pranikah Pada Siswa Sekolah Menengah Pertama Di Kota Bandung. Tidak di publikasi.

Hanifah, F. (2013). Hubungan Kontrol Sosial Orang Tua dengan Perilaku Seks Pranikah Remaja Kelurahan Batang Arau Kecamatan Padang Selatan. Jurnal Spektrum PLS, 1(2).

Horrigan, John B. (2002). New Internet Users: What They Do Online, What They Don't, and Implications for the 'Net's Future.

Muhammad, A. (2011). Cara Kerja Emosi Dan Pikiran Manusia. Jogjakarta: Diva Press.

Noviana, A. P. R. (2016). Hubungan tingkat penggunaan smartphone pada remaja dengan interaksi dalam keluarga. Retrieved 27 February, 2018, from 
http://repository.ipb.ac.id/handle/12345 6789/81921

Pramana, Agung Widhi. (2018). Hubungan Antara Waktu Penggunaan Gadget Dengan Kontrol Diri Pada Anak Yang Bermain Video Game Online. Retrieved 22 September,2018, from https://dspace.uii.ac.id/bitstream/handle /123456789/6956/Skripsi\%20Agu ngWidhiPramana\%20\%2811320116\%2 9.pdf? sequence $=2$ \&isAllowed $=y$

Pusat Kajian Komunikasi Universitas Indonesia (PUSKAKOM). (2015). Profil Pengguna Internet Indonesia 2014.Jakarta: Asosiasi Penyedia Jasa-Internet Indonesia. Retrieved October 27, 2017, from http://puskakom.ui.ac.id/wpcontent/uploads/2017/01/Survey-APJII2014- v2.pdf

Putra, M,D. (2015). Hubungan antara Penggunaan Smartphone dengan Ketergantungan Berinteraksi di Dunia Maya (Studi Pada Mahasiswa Pengguna Smartphone Jurusan Sosiologi Angkatan Tahun 2011-2014 FISIP Universitas Lampung. Fakultas FISIP Universitas Lampung.

Putri, Amalia VirnAnda. (2015). Dampak Negatif Penggunaan Smartphone. Retrieved 19 December 2017, from http://www.kompasiana.com/amaliavirn
Andaputri/dampak-negatifpenggunaan-smartphone _552a156b6ea8342e74552d30.

Rika, Devi Purnomo. (2012). Hubungan Self Control Dengan Tingkat Adiksi Bermain Game Online. Skripsi S1 tidak dipublikasi.

Swarjana, I Ketut. (2016). Keperawatan Kesehatan Komunitas. Yogyakarta: ANDI.

Sugiyono. (2014). Metode Penelitian Kuantitatif, Kualitatif dan $R \& D$. Bandung: Alfabeta.

Thomee, S., Harenstam, A., \& Hagberg, M. (2011). Mobile phone use and stress, sleep disturbances, and symptoms of depression among young adults - a prospective cohort study. BMC Public Health, 11(66).

UNICEF Indonesia. (2014). Studi Terakhir: Kebanyakan Anak Indonesia sudah online, namun masih banyak yang tidak menyadari potensi resikonya. Jakarta.

https://www.unicef.org/indonesia/id/me dia_22169.html

Widiana, H. S., Retnowati, S., \& Hidayar, R. (2004). Kontrol Diri dan Kecenderungan Internet. Humanitas: Indonesian Psychological Journal, 1 (1), 6-16. 